\title{
Fire Hazards of Dry Versus Watered Christmas Trees
}

\author{
Matthew S. Hoehler \\ Matthew F. Bundy \\ Laurean DeLauter \\ Robin Materese \\ Leon Geršković \\ José Ricardo García
}




\title{
NIST Technical Note 2131
}

\section{Fire Hazards of Dry Versus Watered Christmas Trees}

\author{
Matthew S. Hoehler \\ Matthew F. Bundy \\ Laurean DeLauter \\ Fire Research Division \\ Engineering Laboratory \\ Robin Materese \\ Leon Geršković \\ José Ricardo García \\ Public Affairs Office \\ NIST Directors Office
}

This publication is available free of charge from:

https://doi.org/10.6028/NIST.TN.2131

December 2020

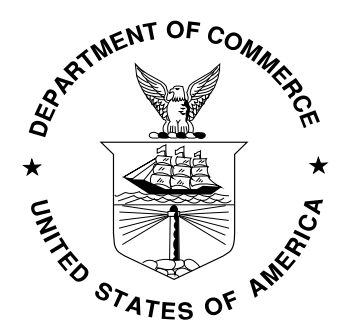

U.S. Department of Commerce Wilbur L. Ross, Jr., Secretary

National Institute of Standards and Technology Walter Copan, NIST Director and Undersecretary of Commerce for Standards and Technology 
Certain commercial entities, equipment, or materials may be identified in this document to describe an experimental procedure or concept adequately. Such identification is not intended to imply recommendation or endorsement by the National Institute of Standards and Technology, nor is it intended to imply that the entities, materials, or equipment are necessarily the best available for the purpose.

National Institute of Standards and Technology Technical Note 2131 Natl. Inst. Stand. Technol. Tech. Note 2131, 16 pages (December 2020) CODEN: NTNOEF

This publication is available free of charge from: https://doi.org/10.6028/NIST.TN.2131 


\begin{abstract}
These experiments were designed to examine the difference in fire hazard between a dry Christmas tree and a watered Christmas tree for fire safety awareness. One dry tree (no water after harvesting) and one watered tree was tested with no replicates.

The test specimens were approximately $2.1 \mathrm{~m}$ (7 ft.) tall Douglas fir trees cut fresh from a local Maryland tree farm approximately four weeks prior to testing. The watered tree was placed in a bucket of water within 3 hours of being harvested and a fresh cut was made approximately $50 \mathrm{~mm}$ ( $2 \mathrm{in}$.) from the base of the trunk prior to placement in the water. Both the dry tree and watered tree were stored indoors until the day of the test.

For fire testing, each tree was placed in a mockup of a corner of a living room constructed to provide background for video recording and not to replicate a specific or typical living room. The ignition source was a book of matches with the match heads wrapped with a thin nickelchromium wire that heats, igniting the matchbook, when electricity is applied.

Three attempts were made to ignite the watered tree during which the ignition source and position of fuel adjacent to the ignition source were varied, however, no sustained ignition of the tree was achieved. For the dry tree, ignition of the tree was achieved on the first attempt and a peak heat release rate of $7362 \mathrm{~kW}$ was reached $31 \mathrm{~s}$ after ignition.

Data and video from these experiments are available in the Fire Calorimetry Database [1].
\end{abstract}

\title{
Key words
}

Christmas Tree; Holiday Fire Safety; Fire Calorimetry Database

\section{Acknowledgments}

This work was funded by the National Institute of Standards and Technology (NIST). The authors thank Isaac Leventon of the NIST Fire Research Division and Fran Weber in the NIST Public Affairs Office for their support of these experiments. 


\section{Table of Contents}

1. Scope and Objectives......................................................................................1

2. Test Setup and Procedure .................................................................................2

2.1. Tree specimens and conditioning.................................................................2

2.2. Room corner mockup .............................................................................. 3

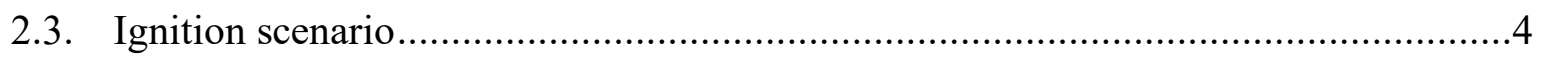

2.4. Instrumentation ..................................................................................4

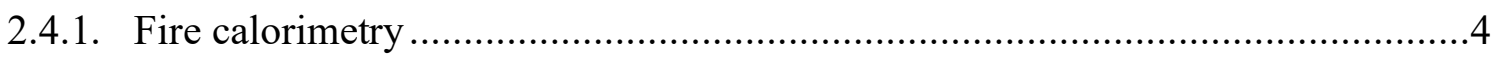

2.4.2. Video cameras ....................................................................................

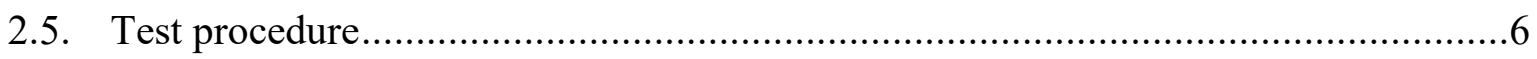

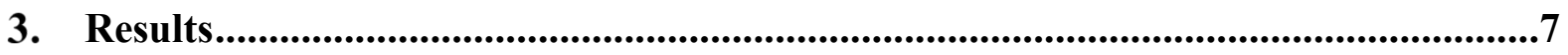

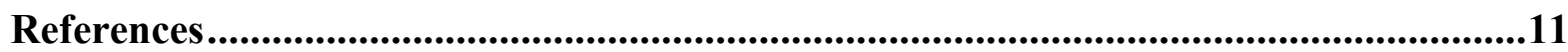




\section{Scope and Objectives}

According to the National Fire Protection Association (NFPA), between 2014 and 2018 fire departments in the United States responded to an average of 160 home fires each year started with a Christmas tree [2]. Although Christmas tree fires are infrequent, when they occur, they can be dangerous and costly. These fires cause an annual average of 2 civilian deaths, 14 civilian injuries, and \$10.3 million in property damage [3] in the United States.

Previous experimental studies conducted at the National Institute of Standards and Technology (NIST) have focused on the characterization of fires in specific species of trees [4] and the numerical modeling of these fires [5]. Additionally, numerous institutions conduct tree burns to promote holiday fire safety; e.g. [6]-[8].

The experiments presented in this report were designed by staff at the NIST National Fire Research Laboratory (NFRL) and Public Affairs Office (PAO) to examine the difference in fire hazard between a properly maintained (watered) Christmas tree and dry Christmas tree for fire safety awareness. One watered tree and one dry tree (no water after harvesting) was tested with no test replicates. For fire testing, each tree was placed in a mockup of a corner of a living room constructed to provide background for video recording and not to replicate a specific or typical living room. The fire behavior of artificial trees was not considered. 


\section{Test Setup and Procedure}

\subsection{Tree specimens and conditioning}

Four approximately $2.1 \mathrm{~m}(7 \mathrm{ft}$.) tall Douglas fir trees were cut fresh from a local Maryland tree farm on October $5^{\text {th }}, 2017$; approximately four weeks prior to testing (Fig. 1). The trees were transported to the NFRL and stored indoors until the day of the test. Two trees were placed in buckets of water within 3 hours of harvesting and a fresh cut was made approximately $50 \mathrm{~mm}$ ( $2 \mathrm{in}$.) from the base of the trunk prior to placement in the water (Fig. 2a). The water in the buckets was refilled regularly until the day of the fire test; i.e., the trees always had water. The other two trees were nailed to plywood bases and not given water (Fig. 2b). Four trees were harvested to have backups in case of problems during conditioning or testing, however, only one dry and one watered tree were fire tested. The mass and dimensions of the trees were not measured.

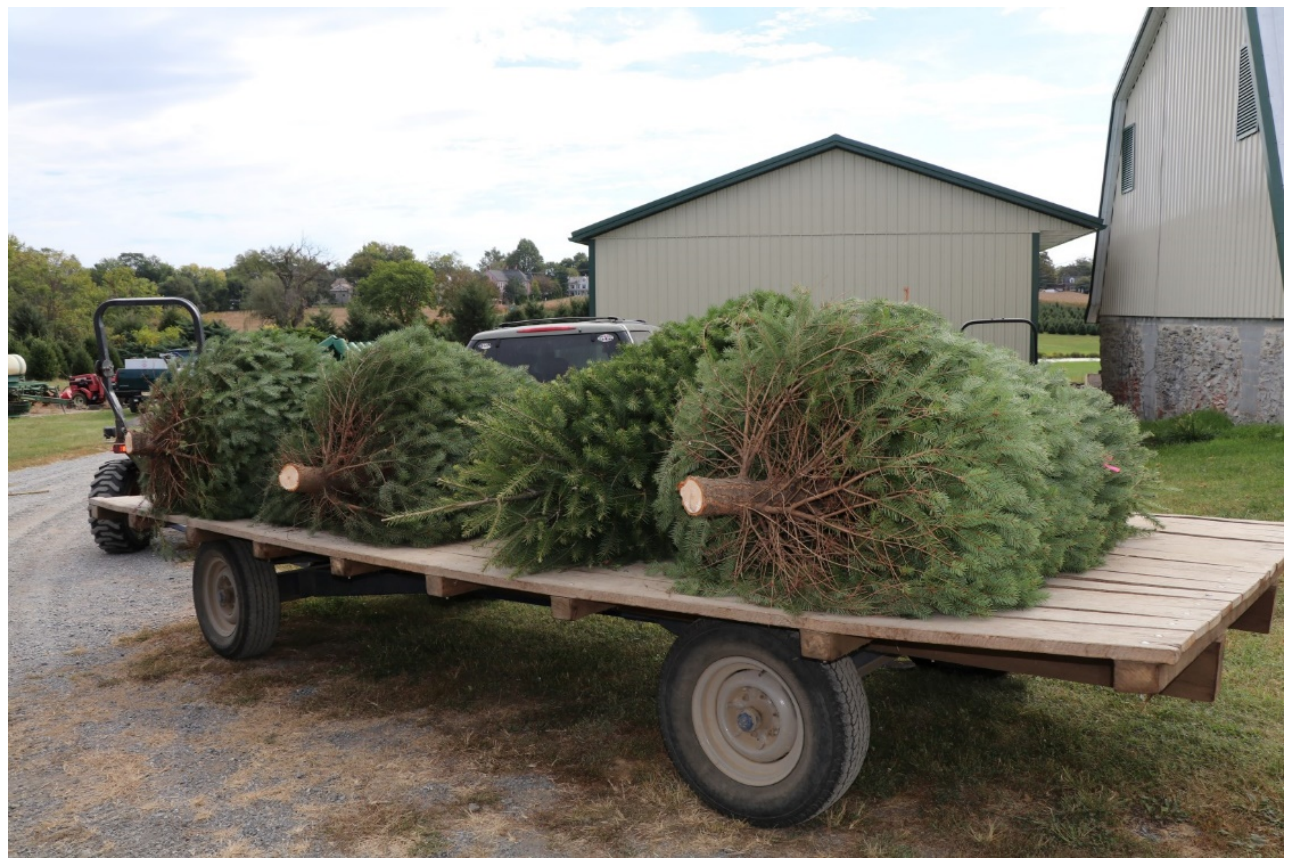

Fig. 1. Photograph of the trees shortly after they were cut.

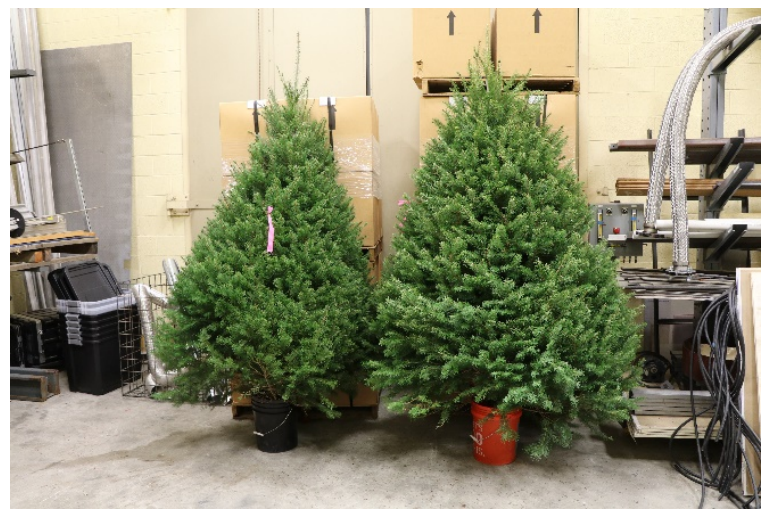

(a)

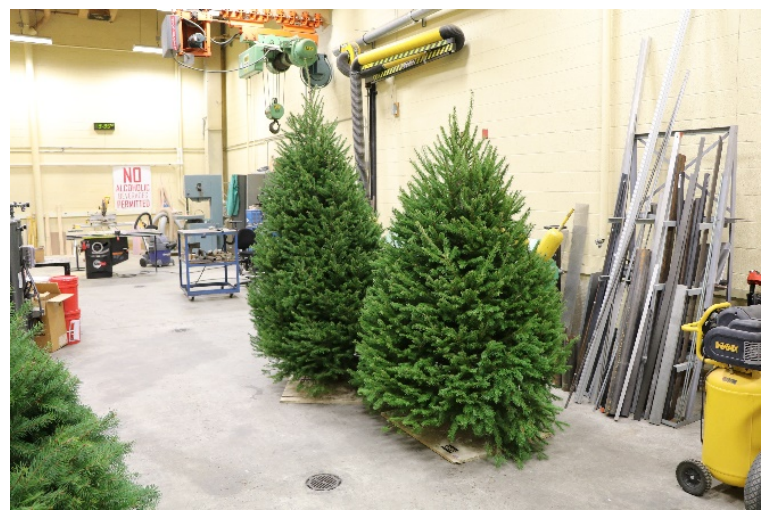

(b)

Fig. 2. Photograph of conditioning of the trees prior to testing: (a) watered and (b) dry. 


\subsection{Room corner mockup}

The trees were tested in a mockup of a corner of a living room designed to provide background for video recording (Fig. 3). The ceiling height was approximately $2.4 \mathrm{~m}$ ( $8 \mathrm{ft}$.). The setup was constructed without a soffit to allow combustion products (smoke) to rise to the exhaust hood more easily with less obscuration of the video. The room corner was rebuilt for each test using identical furnishings including an upholstered wing chair, a wood table, a shelf with miscellaneous objects, a carpet, and a painting. The laboratory floor was covered with $16 \mathrm{~mm}$ (5/8 in.) thick Type $\mathrm{X}$ gypsum boards to limit heat transfer to the concrete. The mass and location of the furnishings were not measured.

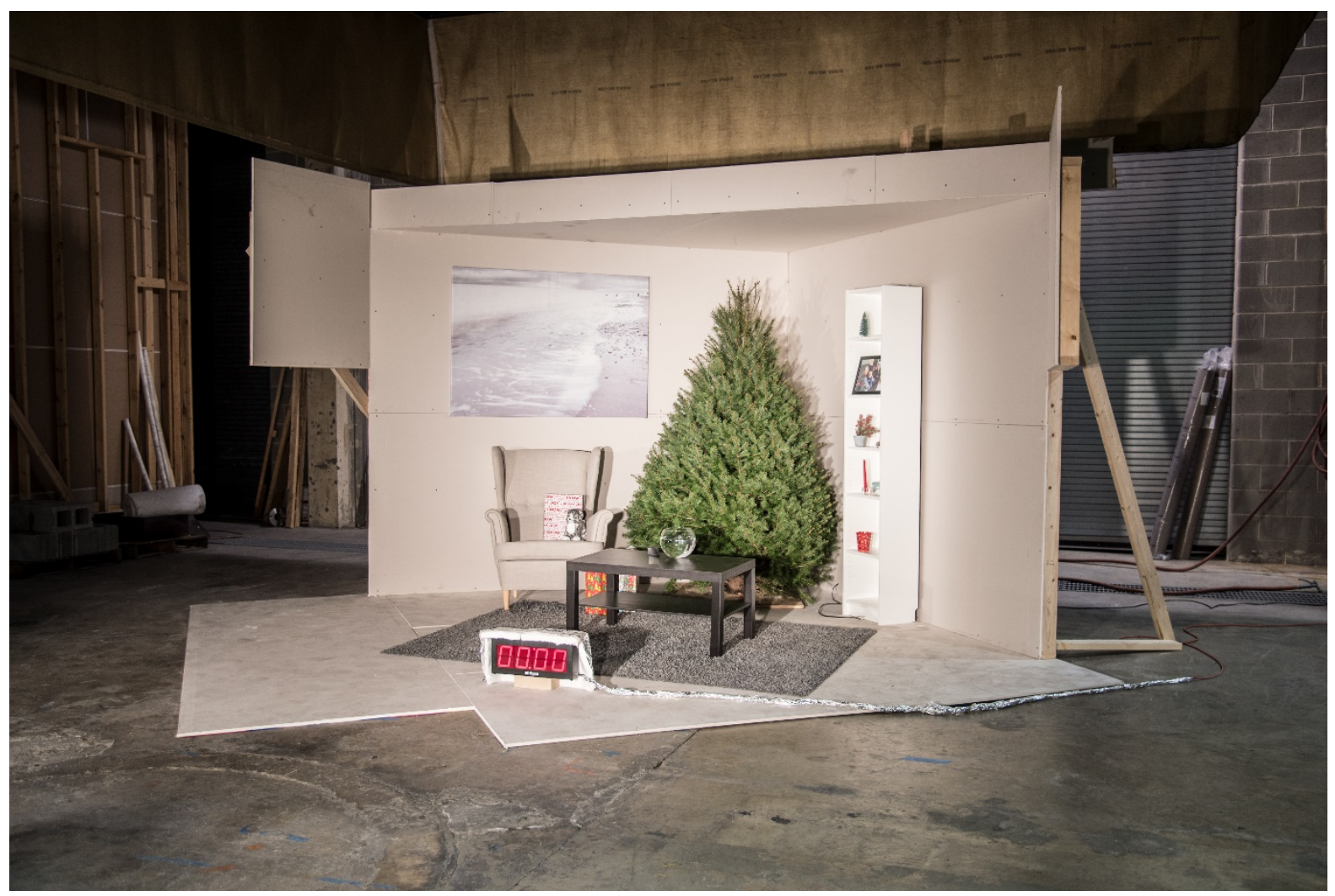

Fig. 3. Photograph of room corner test setup. 


\subsection{Ignition scenario}

The ignition source was a book of matches with the match heads wrapped with a thin nickelchromium wire that heats when electricity is applied allowing safe, remote ignition of the tree. This is often referred to as an "electric match." The electric match was placed in the branches in the lower third of the tree. After the first unsuccessful attempt to ignite the watered tree, two books of matches were used to create a larger source as seen in Fig. 4 for the remainder of the ignitions for both the watered and dry tree.

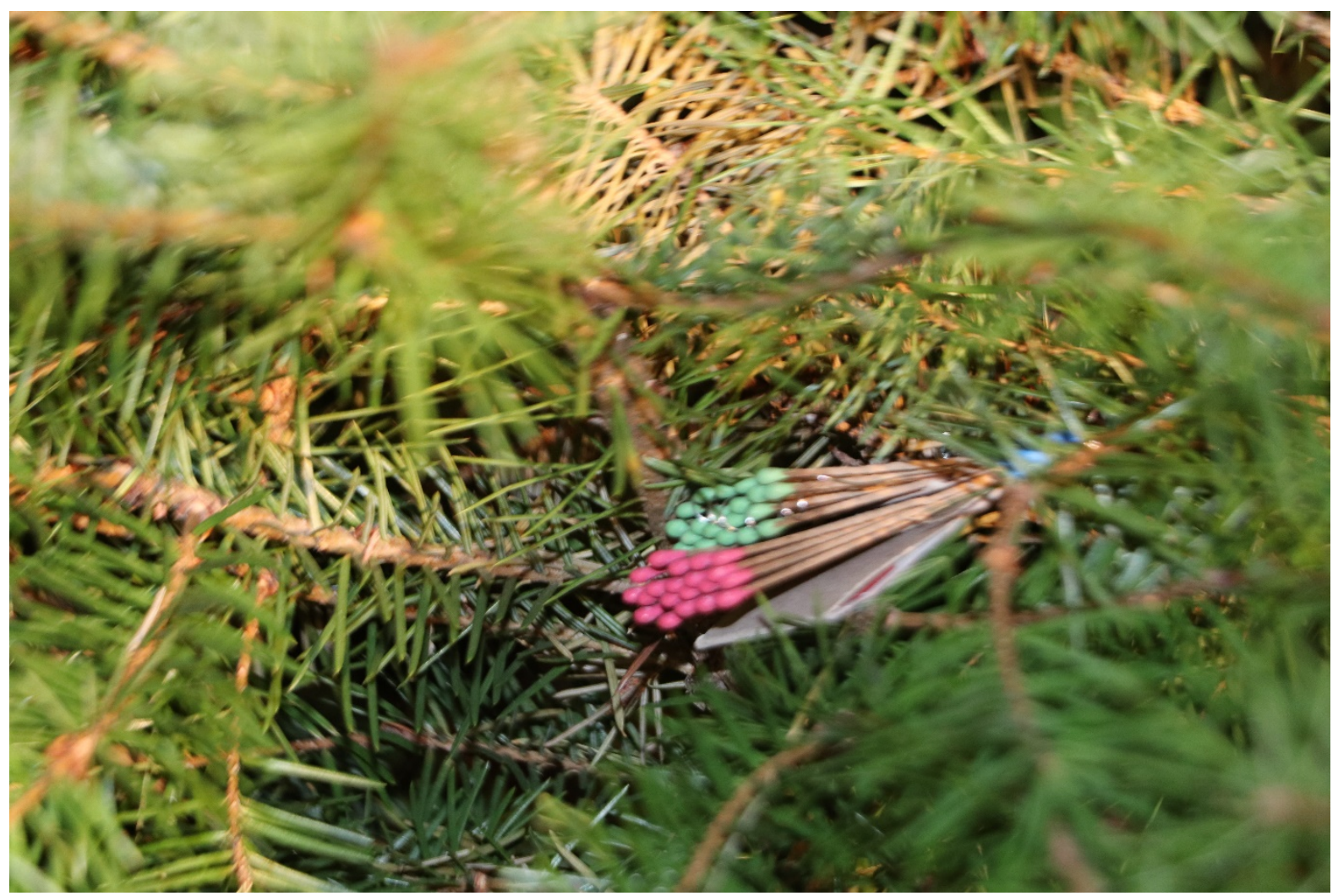

Fig. 4. Photographs of fire ignition source (electric match) with two match books.

\subsection{Instrumentation}

The instrumentation used in these experiments was limited to data acquired using the NIST $20 \mathrm{MW}$ calorimetry measurement system and video cameras. A digital timer with a large (red) light emitting diode (LED) display was placed in view of the cameras. The display showed seconds and deci-seconds for the first $60 \mathrm{~s}$ and then switched to minutes and seconds. For example, the photograph of "ignition" for the watered tree in Section 3 shows 00:58 (or $580 \mathrm{~ms}$ ). The digital timer was used with the video to confirm the times reported by the calorimeter data acquisition system. Slight discrepancies $(<2 \mathrm{~s})$ between the calorimeter event time and image clock time may exist due to lack of synchronization of the clocks.

\subsubsection{Fire calorimetry}

The calorimetry measurement system at the NFRL allows for measurement of heat release by 1) the principle of oxygen consumption calorimetry and 2) the principle of fuel consumption calorimetry (consumption of natural gas). The NFRL utilizes large canopy exhaust hoods to capture fire effluents for quantification of the heat release as a function of time. The system 
includes an emissions control system (ECS) to treat smoke particulates and combustion gases to comply with local environmental requirements. The facility has four canopy hoods, each denoted by its maximum fire capacity: $0.5 \mathrm{MW}(3.1 \mathrm{~m} \times 3.2 \mathrm{~m}), 3 \mathrm{MW}(6.1 \mathrm{~m} \times 6.1 \mathrm{~m})$, $10 \mathrm{MW}(8.4 \mathrm{~m} \times 12.4 \mathrm{~m})$, and $20 \mathrm{MW}(13.8 \mathrm{~m} \times 15.4 \mathrm{~m})$. The average expanded uncertainty in the normal operating range for each hood for generic combustible fuel is $7.9 \%, 6.8 \%$, $8.7 \%$, and $9.8 \%$, respectively. This uncertainty is valid for near steady state fires. Transient events (less than $30 \mathrm{~s}$ ) may have larger uncertainty because of system response time. The range of expanded uncertainty for the natural gas (fuel consumption) verification burners is $1.4 \%$ to $1.8 \%$. Detailed information on the NFRL calorimetry measurement system is provided by Bryant and Bundy [9].

These experiments utilize only oxygen consumption calorimetry on the $6 \mathrm{~m}$ hood with an exhaust flow rate of approximately $21 \mathrm{~kg} / \mathrm{s}$. This exhaust flow rate is sufficient to capture all the combustion products for this experiment due to the short duration of the peak burning.

\subsubsection{Video cameras}

High-definition video of the experiments was captured using several digital video cameras at a large stand-off from the room corner (Fig. 5). Close up video footage of the tree was captured using a waterproof sports action camera placed in a water-filled glass globe on the table directly in front of the tree (Fig. 6). The water served the dual purposes of cooling the camera and filtering out the infrared thermal radiation produced by the fire that would otherwise damage the camera's imaging sensor. This concept was later developed to house $360^{\circ}$ cameras as described by Hoehler [10].

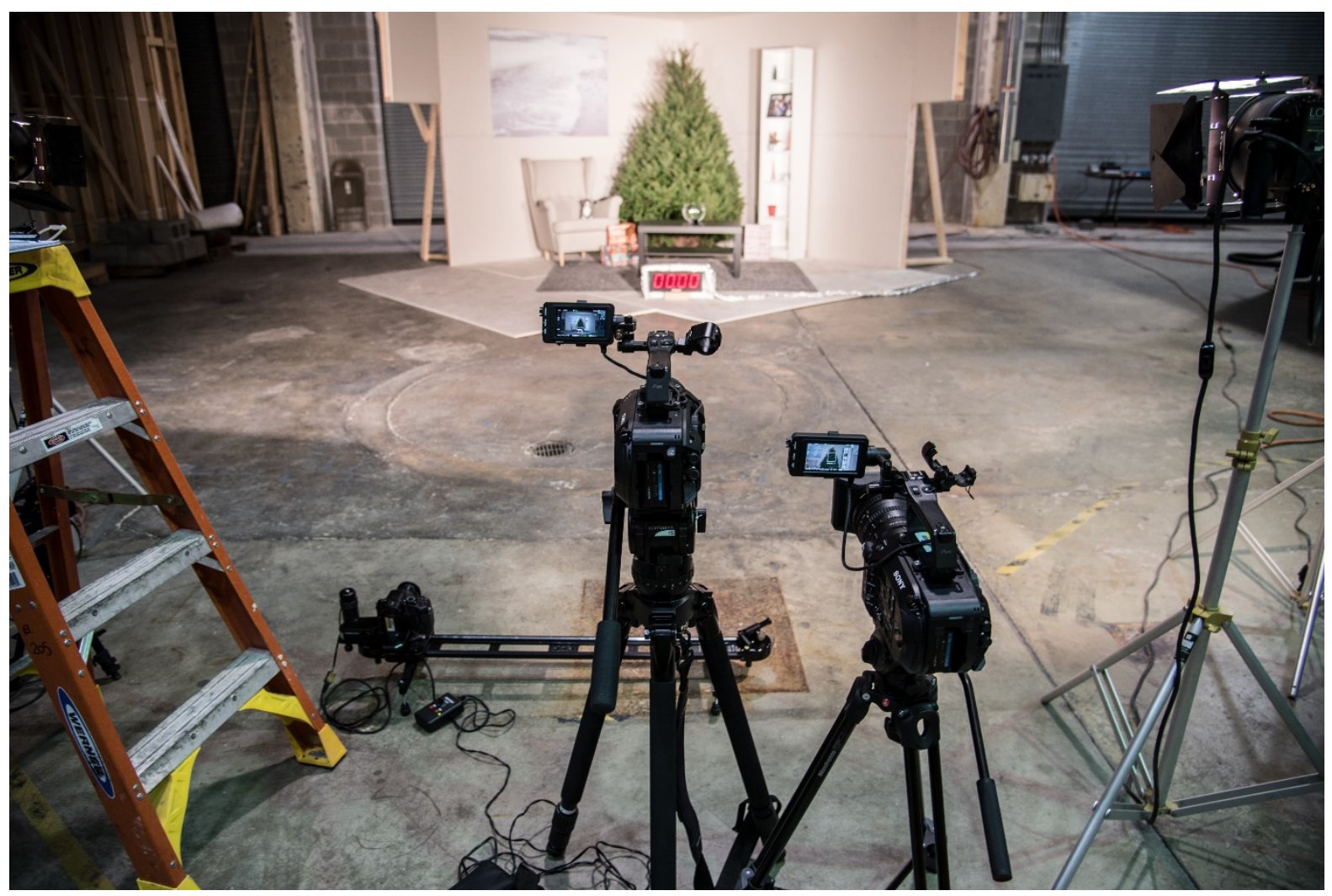

Fig. 5. Photograph of the video camera setup. 


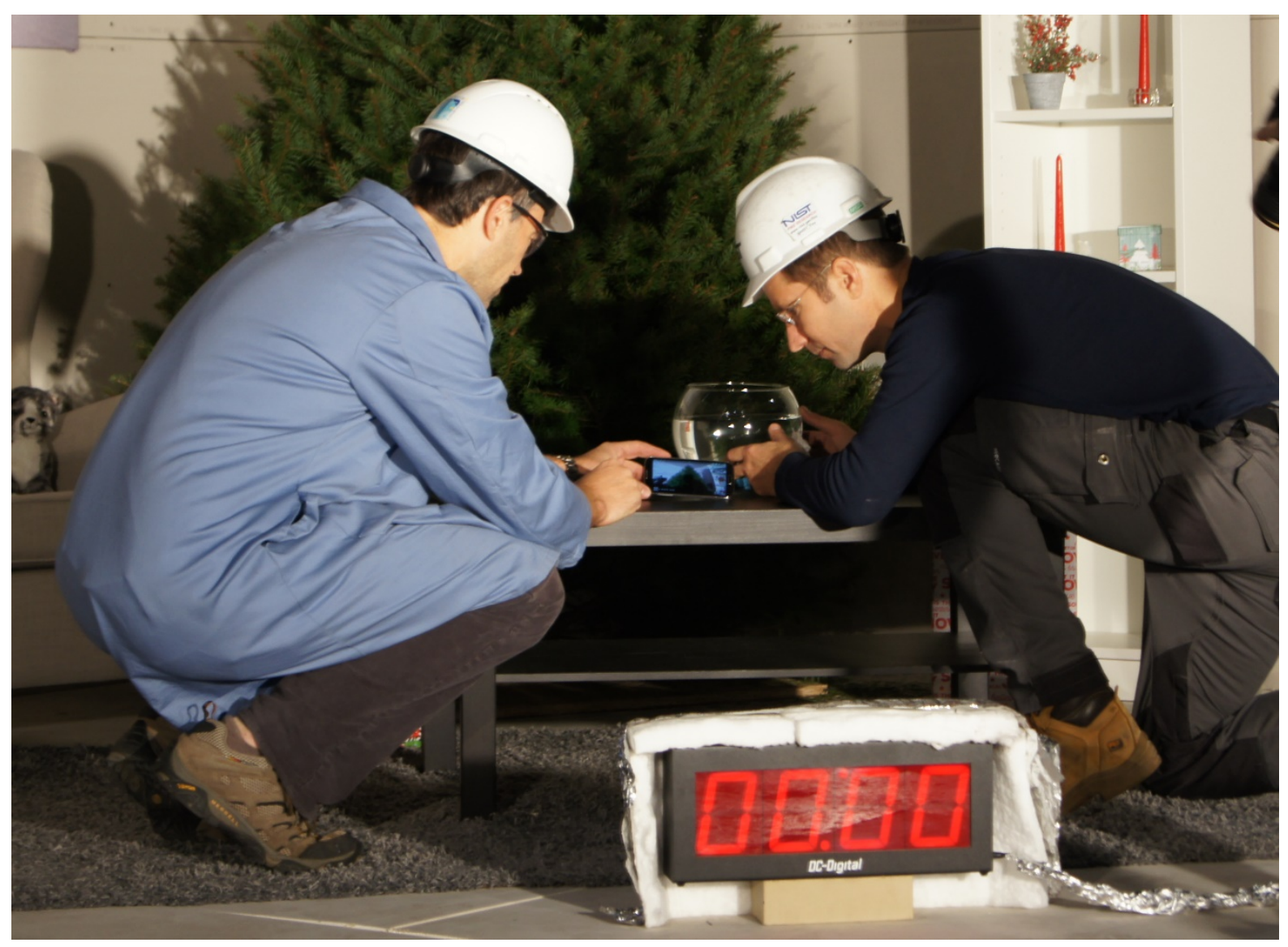

Fig. 6. Photograph of the setup used for the water-cooled video camera.

\subsection{Test procedure}

The following procedure was used:

1. Pre-test

a. Call the NIST Fire Department to deactivate automatic fire suppression.

b. Turn on exhaust fans and open makeup air dampers.

c. Verify that area carbon monoxide detectors and alarms are functioning.

d. Turn on measurement systems and verify that they are functioning.

e. Turn on lighting and verify camera settings.

f. Prepare the ignition source.

2. Test Director conducts Safety Briefing and completes safety checklist.

3. Start data acquisition and turn on video cameras and audio recording.

4. Acquire background data for Heat Release Rate.

5. Ignite fire using electric match.

6. Collect experimental data and video.

7. Stop data acquisition: The test will proceed until total fuel burnout unless the Test Director, in consultation with the Safety Officer, decide to suppress the fire.

8. Post-test/Tear-down:

a. Safety Officer calls NIST fire department to reactivate automatic fire suppression systems.

b. Debris and material are properly stored or discarded by NFRL staff. 


\section{Results}

Downloadable data and video from these experiments are available in the NIST Fire Calorimetry Database [1]. Behind the scenes photos and the final videos from the NIST Public Affairs Office are available at https://www.nist.gov/topics/fire/why-you-shouldwater-your-christmas-tree. Due to the limited number of tests conducted and because the room corner was not designed to replicate real conditions, these results should not be extrapolated.

Three attempts were made to ignite the watered tree; however, no sustained ignition of the tree was achieved. After the first attempt, a second match book was added to the electric match to create a larger fire source. For the third attempt, two match books were used, and the electric match was placed in an area of the tree with the most significant drying of the needles. In the third attempt, the fire initially grew as the needles adjacent to the matches ignited, however the fire then self-extinguished. The measured heat release rate (HRR) for the third attempt is shown in Fig. 7. A peak heat release rate of $6.7 \mathrm{~kW}$ was reached $71 \mathrm{~s}$ after ignition. This fire size is well below the normal operating range and outside the range of confirmation tests with the reference burner. The peak heat release rate is at the limit of detection for this calorimeter and not well quantified. A sequence of images associated with key events is provide in Table 1.

For the dry tree, ignition of the tree was achieved on the first attempt and the fire grew rapidly. The measured heat release rate is shown in Fig. 8. A peak heat release rate of $7362 \mathrm{~kW}$ was reached $31 \mathrm{~s}$ after ignition. A sequence of images for key events is provide in Table 2.

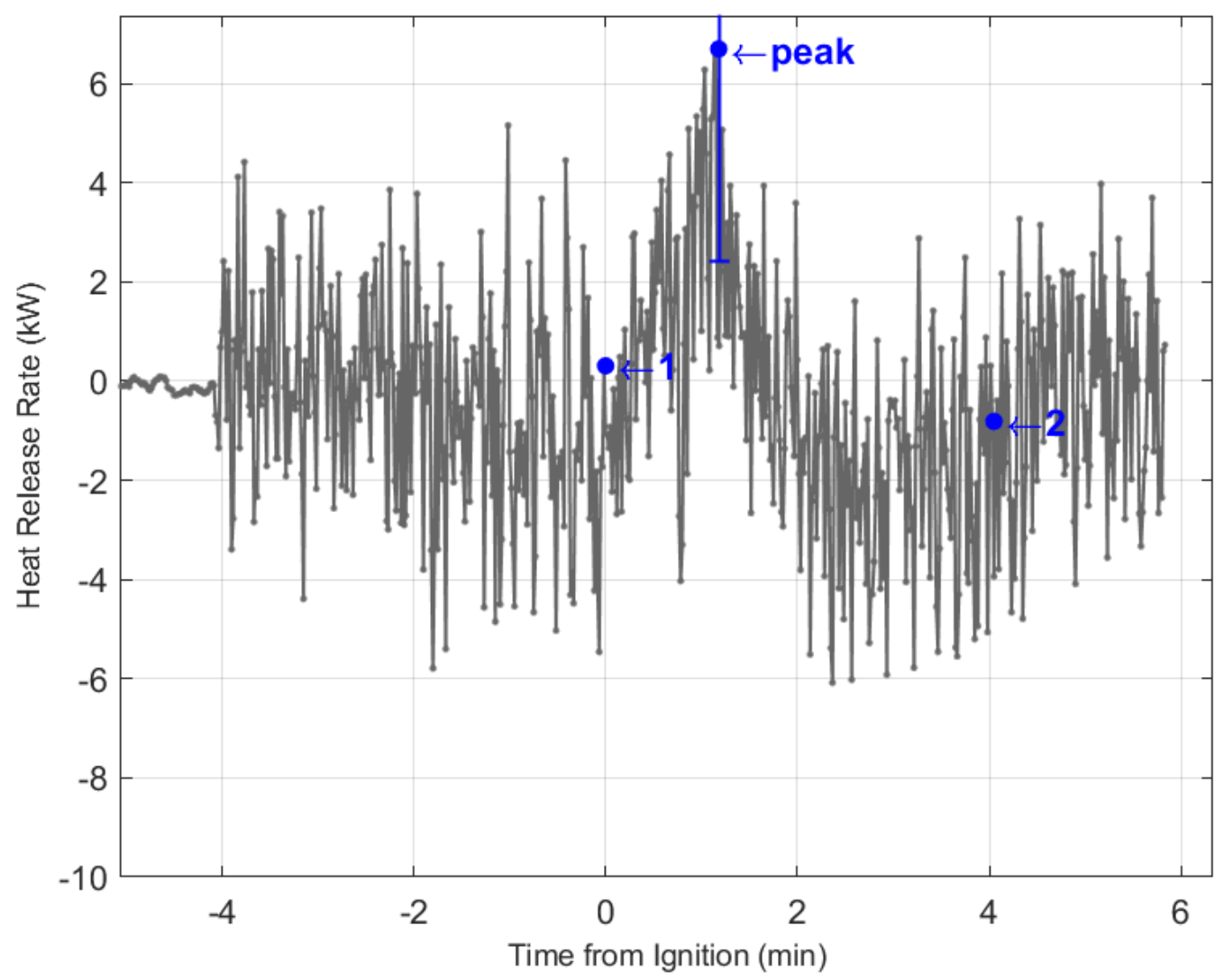

Fig. 7. Plot of Heat Release Rate data with event markers and error bars (combined expanded uncertainty) shown at peak for the watered tree. 
Table 1. Summary of observed test events for the watered tree.

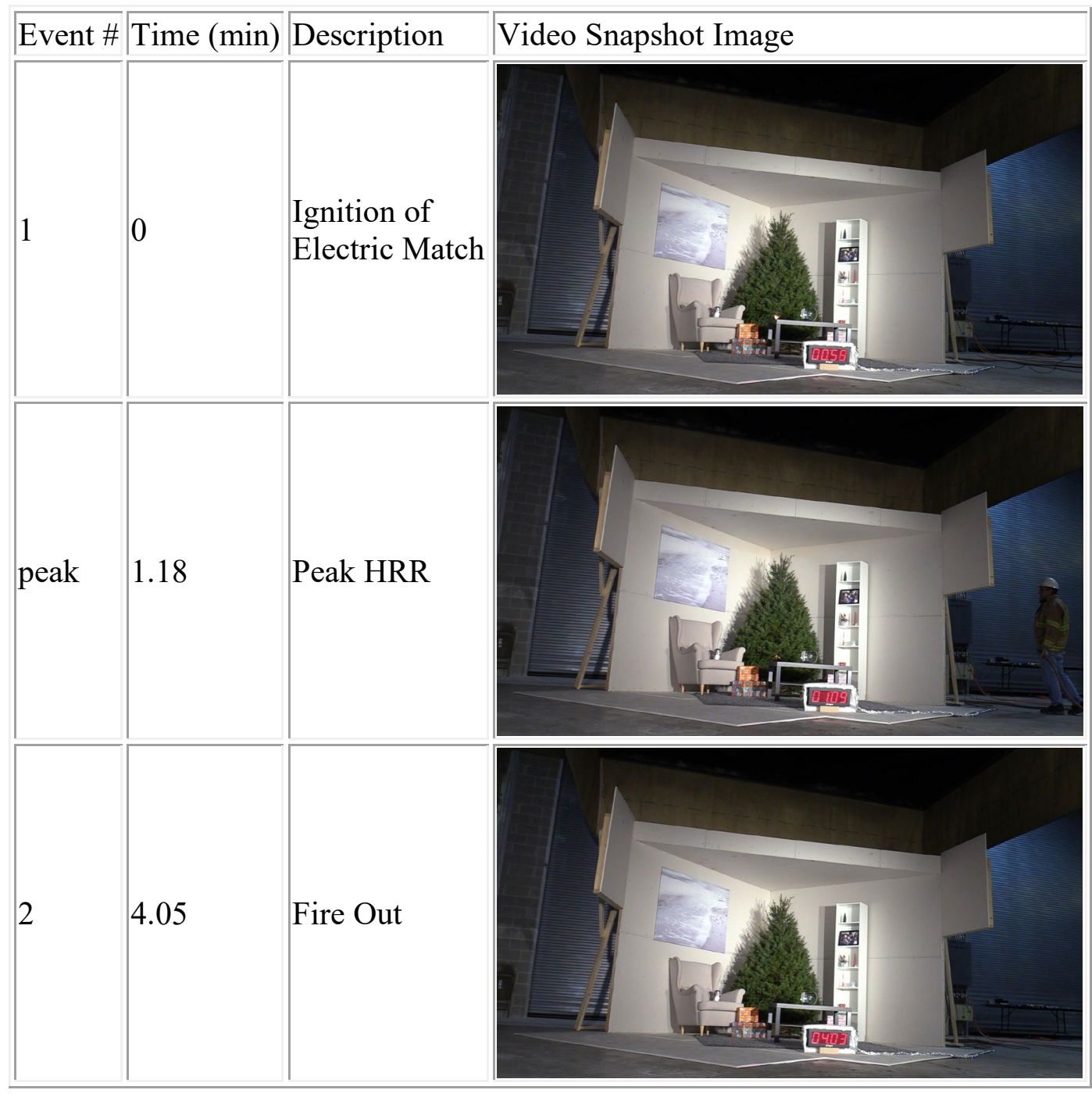




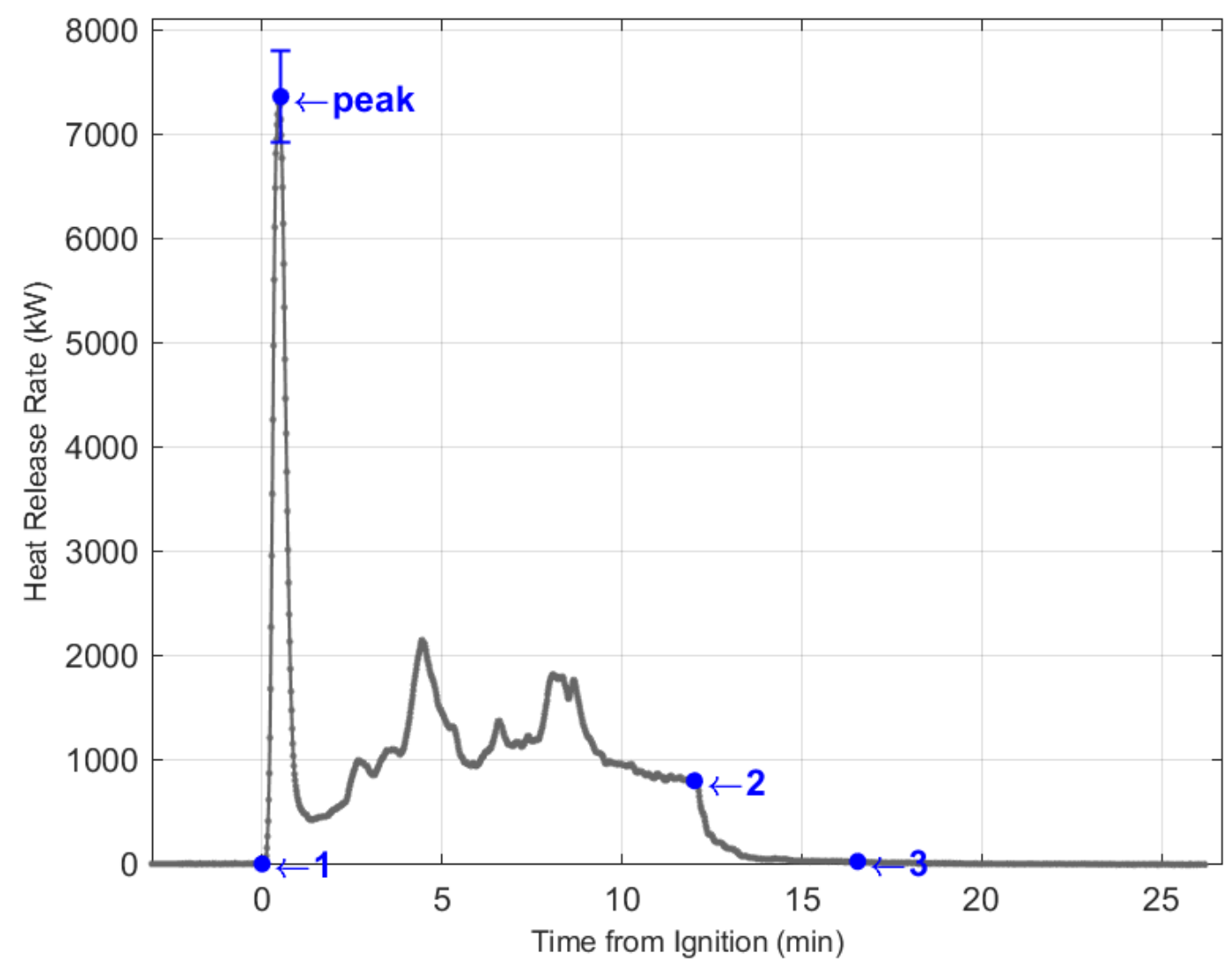

Fig. 8. Plot of Heat Release Rate data with event markers and error bars (combined expanded uncertainty) shown at peak for the dry tree. 
Table 2. Summary of observed test events for the dry tree.

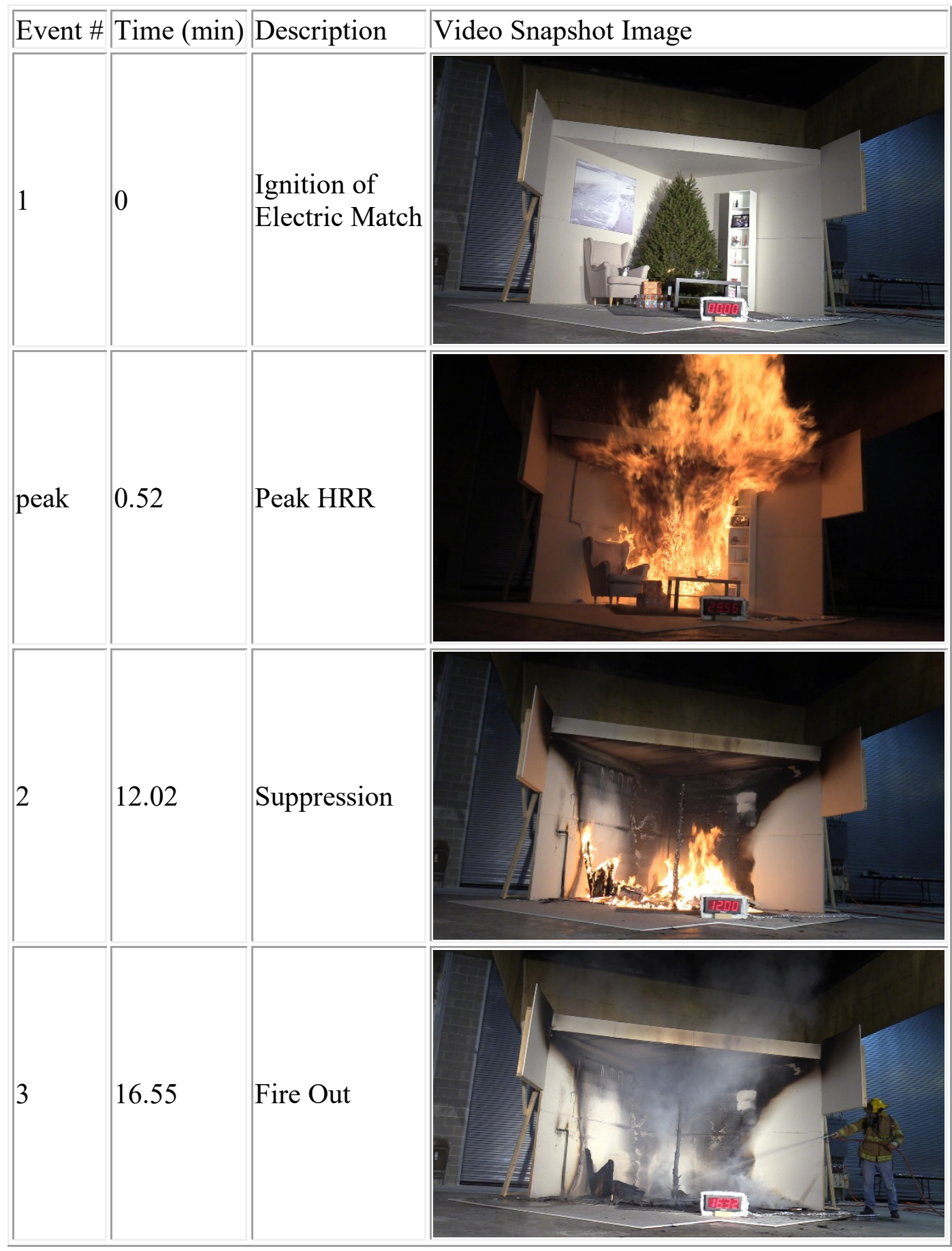




\section{References}

[1] "NIST Fire Calorimetry Database," 2020. https://www.nist.gov/el/fcd.

[2] National Fire Protection Association (NFPA), "NFPA - Winter holidays." https://www.nfpa.org/Public-Education/Fire-causes-and-risks/Seasonal-firecauses/Winter-holidays (accessed Dec. 08, 2020).

[3] M. Ahrens and R. Maheshwari, "Christmas Tree Fires,” 2020.

[4] D. W. Stroup, L. Delauter, J. Lee, and G. Roadarmel, "Scotch Pine Christmas Tree Fire Tests - Report of Test 4010," 1999. [Online]. Available: https://tsapps.nist.gov/publication/get_pdf.cfm?pub_id=907753.

[5] W. Mell, A. Maranghides, R. McDermott, and S. L. Manzello, "Numerical simulation and experiments of burning douglas fir trees," Combust. Flame, vol. 156, no. 10, pp. 2023-2041, Oct. 2009, doi: 10.1016/j.combustflame.2009.06.015.

[6] W. P. Insititute, "Fire Protection Engineers Show Dangers of Dry Christmas Tree." https://www.wpi.edu/news/seasonal-safety-wpi-fire-protection-engineeringresearchers-show-dangers-dry-and-neglected (accessed Dec. 08, 2020).

[7] U. of Maryland, "Christmas Tree Fire Safety Demonstration | Department of Fire Protection Engineering." https://fpe.umd.edu/events/christmas-fire-safety-demo (accessed Dec. 08, 2020).

[8] "UL FSRI - Fire Safety Research Institute - Holiday Fire Safety Video Featuring Close Before You Doze." https://ulfirefightersafety.org/posts/holiday-fire-safetyvideo.html (accessed Dec. 08, 2020).

[9] R. A. Bryant and M. F. Bundy, "The NIST 20 MW calorimetry measurement system for large-fire research," Gaithersburg, MD, Dec. 2019. doi: 10.6028/NIST.TN.2077.

[10] M. S. Hoehler, "On the development of a transparent enclosure for $360^{\circ}$ video cameras to observe severe fires in situ," Fire Saf. J., no. xxxx, p. 103024, 2020, doi:

10.1016/j.firesaf.2020.103024. 